\title{
Thermotropic Gel-Forming and Sol-Forming Systems for Enhanced Oil Recovery and Technologies of Their Joint Application with Thermal Methods for Oil Production
}

\author{
L.K. Altunina and V.A. Kuvshinov
}

\begin{abstract}
The study of the kinetic, physicochemical, and rheological characteristics of solutions, gels and sols for enhanced oil recovery, water shutoff, and stimulation of oil production resulted in the creation of thermotropic systems, based on inorganic and polymer solutions, which are capable to generate a gel or sol in situ, and sol-forming oil-displacing surfactant-based systems with controlled viscosity and alkalinity. The thermal reservoir energy or that of the injected heat carrier is a factor causing solation and gelation. The technologies using the created systems are proposed for complicated operating conditions, including high-viscosity oilfields being developed by thermal-steam stimulation, and a complex of injection options: gradient and component-wise injection, reagent cycling. The technologies were successfully tested in the Permian-Carboniferous reservoir of high-viscosity oil in the Usinsk oilfield, including joint thermal-steam stimulation of the reservoir. The results correspond to the world level.
\end{abstract}

Keywords Enhanced oil recovery $\cdot$ Physicochemical methods $\cdot$ High-viscosity oil Thermal methods - Surfactants - Sols - Thermotropic systems • Inorganic and polymer gels · Technologies · Gradient and component-wise injections Water shutoff

Currently in the world and in Russia, most of major oilfields are at later stages of their development with a high water cut, especially oilfields developed by water flooding and thermal-steam stimulation. The current oil recovery factor is often less than $20 \%$. Therefore application of physicochemical methods for enhanced oil

L.K. Altunina $(\bowtie) \cdot$ V.A. Kuvshinov

IPC SB RAS - Institute of Petroleum Chemistry SB RAS, Tomsk, Russia

e-mail: alk@ipc.tsc.ru

V.A. Kuvshinov

e-mail: vak2@ipc.tsc.ru

(C) The Author(s) 2018

K.V. Anisimov et al. (eds.), Proceedings of the Scientific-Practical Conference

"Research and Development - 2016", https://doi.org/10.1007/978-3-319-62870-7_32 
recovery, especially for water shutoff using gel technologies, is becoming actual [3, p. $2 ; 7$, pp. 8-9; 8, p. 51].

The relevance of the research on the project is determined by the necessity to: improve the efficiency of the basic method of oil production in Russia-flooding and thermal methods for production of high-viscosity oils; decrease (stabilize) water cut of the producing oil; expand the scope of application of the technologies for enhanced oil recovery (EOR technologies) and water shutoff and provide the oil industry with effective domestic agents.

The project is aimed to improve the efficiency of oil production by water flooding and thermal methods due to combining them with physicochemical EOR methods and provide the oil industry with effective EOR technologies and domestic agents for their implementation.

Objectives of the project: to develop and study new compositions of the gel- and sol-forming high-viscosity systems intended to enhance oil recovery, decrease water cuttings of well production and stimulate oil production in abnormal operating conditions, including high-viscosity oilfields being developed by thermal-steam stimulation; to create EOR technologies applying new gel- and sol-forming systems and procedures of their injection combined with thermal methods of high-viscosity oil production, such as the injection of hot water and steam, and to test EOR technologies in field conditions.

Research objectives:

- to develop thermotropic inorganic and polymer systems in situ generating gels or sols, which create deflecting screens; surfactant-based gelled system with controlled viscosity and alkalinity to increase an oil displacement factor and conformance at thermal-steam stimulation and to carry out experimental laboratory research;

- to develop technologies for enhanced oil recovery and selective water shutoff, procedures of the systems injection; technology for component-wise system injection for in situ generation of gels due to hydrodynamic dispersion; computer calculation method for injection planning; recommendations concerning the application of EOR technologies.

The fundamental scientific novelty of the research consists: in the use of in situ generation of the thermotropic gels and sols with auto-controlled viscosity based on inorganic and polymer systems to improve the efficiency of water flooding, combined thermal-steam and physicochemical stimulations, as well as surfactant systems enabling to improve the oil recovery due to both increased oil displacement factors and conformance; in technological solutions of the project-joint application of the systems generating in situ mobile sol and immobile gel screens to increase the reservoir coverage and enhance oil recovery at water flooding and thermal-steam stimulation and complex of technological injection options-gradient and component-wise injections, reagent cycling.

Analytical review of scientific information sources: papers in leading foreign and Russian scientific journals, monographs and patents for 2009-2013, the patent 
research to a depth of 20 years and theoretical studies have shown that the proposed trends are novel and promising.

The study on the kinetics of hydrolysis and gelation, the colloid-chemical and rheological characteristics of the solutions, gels and sols resulted in the creation of thermotropic systems, based on inorganic and polymeric solutions, in situ generating a gel or sol and sol-forming oil-displacing systems based on surfactants with controlled viscosity and alkalinity to enhance oil recovery, to stimulate oil production and for water shutoff.

To improve the efficiency of water flooding and thermal-steam stimulation, we have proposed the thermotropic systems, based on inorganic "Al salt-carbamidewater-surfactant" system, generating gel or sol in situ with auto-controlled viscosity by a mechanism of cooperative process. Using the methods of rotational and vibration viscometry in the temperature range of $70-250{ }^{\circ} \mathrm{C}$ to study rheological properties of the gels we have found that aluminum hydroxide gel is a pseudoplastic thixotropic solid-like body of coagulation structure. When surfactants were added to the gel-forming solutions gels viscosity increased considerably.

The studies on rheological properties of sols and gels in "Al salt-carbamidewater" system at different component concentrations using "Reotest-2.1.M" and Haake RheoStress 600 rotational viscometers at different shear stresses have shown that the sols and gels are thixotropic. Thixotropy manifests itself in liquefaction at sufficiently intensive flow or stirring of the gels or sols and their thickening (solidification) after the termination of the mechanical impact. Figure 1 clearly shows the thixotropy manifestation both for the gels and sols-as hysteresis of rheological flow curves: decrease in viscosity is observed with increasing shear rate (forward motion) and increase in viscosity is observed at a subsequent decrease in shear rate (reverse motion). Thixotropy of the sols and gels generated in situ under the influence of the temperature of the injected heat carrier (steam, hot water) in the

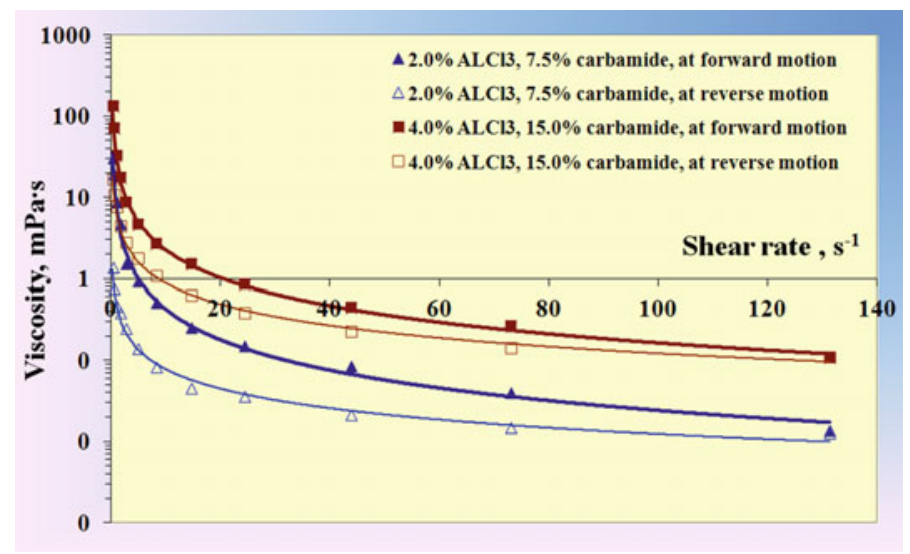

Fig. 1 The viscosity dependence of the sols and gels, prepared from solutions in "Al saltcarbamide-water" system, on the shear rate at the forward and reverse motions 
development of high-viscosity oil deposits, gives additional possibilities to form the deflecting screens in the reservoir to equalize the profile of the heat carrier front and to increase the reservoir coverage with thermal-steam stimulation.

At shear rates ranging from 0.01 to $3 \mathrm{~s}^{-1}$ at high pressures in a uniform compression, the shear stress and viscosity of the gels, prepared from the solutions of the system based on "Al salt-carbamide-water" system, have values several orders of magnitude higher than at the atmospheric pressure. In the oil reservoir, the high pressure and conditions of uniform compression are realized, therefore the thermotropic gel-forming systems can be used to regulate the injectivity profile in injection wells and for water shutoff in production wells, including the thermal-steam and cyclic-steam reservoir stimulations to increase oil recovery.

The studies of physicochemical properties, rheological characteristics and oil-displacing ability of the sol- and gel-forming systems, based on "Al saltcarbamide-water" system added with substances regulating hydrophilic-lipophilic balance and gelation temperature, showed the possibility of their application in field conditions at a reservoir temperature $20-320{ }^{\circ} \mathrm{C}$, with a high water salinity, up to $300 \mathrm{~g} / \mathrm{dm}^{3}$, to regulate filtration flows $[6, \mathrm{p} .1]$, to enhance oil recovery and reservoir coverage at water flooding and thermal-steam stimulation.

To enhance oil recovery and decrease water cut we have created the thermotropic gel- and sol-forming systems based on a polymer with a lower critical solution temperature, the cellulose ether-methylcellulose (MC), which are capable of forming gels (sols) in situ due to a phase transition "solution - gel (sol)". The temperature and gelation time are regulated by inorganic and organic additives, Figs. 2 and 3, their effect is additive. Upon reaching the gelation temperature the viscosity sharply increases-5-200 times. At the shear rates ranging from 0.5 to $5 \mathrm{~s}^{-1}$ the gel is a solid-like body having viscoelastic properties. The gels retain their rheological characteristics at high temperatures - up to $150-220^{\circ} \mathrm{C}$. In the course of time the gels harden.

We have investigated the kinetics of gelation, rheological, and filtration characteristics, oil-displacing ability of the systems based on MC of different grades, we also determined their optimal compositions and physicochemical parameters: the $\mathrm{pH}$ of the solutions - 6.4-7.0, the $\mathrm{pH}$ of the sols and gels - 6.8-8.5; the viscosity of the solutions $-25-100 \mathrm{mPa} \cdot \mathrm{s}$; the viscosity of the sols and gels $-150-3900 \mathrm{mPa} \cdot \mathrm{s}$

Fig. 2 Change in the viscosity of $1 \%$ methyl cellulose MC-100 solution of with various carbamide concentrations after thermostatting at $90{ }^{\circ} \mathrm{C}$, using Haake Viscotester iQ rheometer (measuring system of coaxial cylinders, the CR-mode) equipped with a temperature module on the Peltier elements

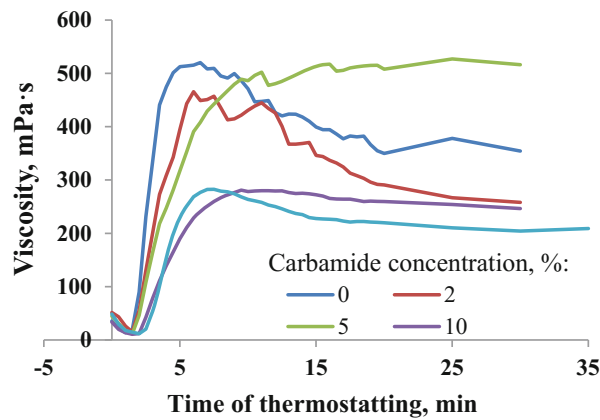




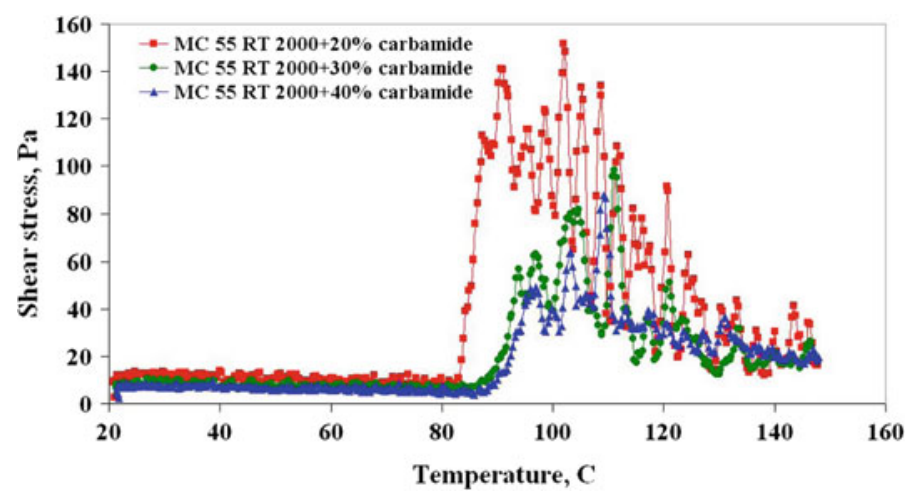

Fig. 3 The temperature dependence of the shear stress for $1.5 \%$ solutions of methyl cellulose MC 200055 RT added with different amounts of carbamide at a shear rate of $3 \mathrm{~s}^{-1}$ using Haake RheoStress 600 rotational viscometer

at low shear rates $\left(0.5-5 \mathrm{~s}^{-1}\right)$, under pressure - up to $90,000-180,000 \mathrm{mPa} \cdot \mathrm{s}$; the density of the solutions - $1000-1080 \mathrm{~kg} / \mathrm{m}^{3}$; gelation time-from several minutes to some days depending on the temperature and composition of the solution; freezing temperature -0 -minus $20^{\circ} \mathrm{C}$. The increase in the oil displacement factor in heterogeneous reservoir models with a permeability of $0.167-9.456 \mu \mathrm{m}^{2}$ ranged from 3 to $21 \%$, thus high absolute values of the oil displacement factor were achieved [4, p. 3].

To enhance oil recovery and stimulate oil production we have created the thermotropic sol-forming oil-displacing systems based on "surfactants - carbamideammonium salt-aluminum salt-water" system with controlled viscosity and alkalinity, which enable to increase not only the oil displacement factor, but also the factor of reservoir coverage by thermal-steam or cyclic-steam stimulations at simultaneous intensification of the development. To create the systems we used a promising concept of using the reservoir energy or that of the injected heat carrier to generate in situ the oil-displacing fluid and sols, which were thermotropic chemical "intelligent" systems, preserving and self-regulating in the reservoir for a long time a complex of colloid-chemical properties, optimal for oil displacement purposes.

In surface conditions the thermotropic sol-forming oil-displacing systems based on "surfactants-carbamide-ammonium salt-Al salt-water" system are low-viscosity liquids, and in reservoir conditions under the influence of the reservoir temperature or that of the injected heat carrier the systems are converted into sols with controlled viscosity and density, high oil-displacing capacity. Thus these systems acquire the rheological and colloidal-chemical properties enabling to use for the formation of mobile blocking screens redistributing filtration flows and increasing the reservoir coverage by the base stimulation and the oil displacement factor. The high oil-displacing properties of the systems are provided by in situ formation of $\mathrm{CO}_{2}$ and ammonia buffer solution with a maximum buffering capacity in the $\mathrm{pH}$ range of 9.0-10.5, which cause a multiple increase in surfactants detergency, decrease oil 
viscosity and swelling of clay minerals in reservoir-rock. In situ thermotropic solation due to carbamide hydrolysis and the conjugated process of hydrolytic polycondensation of aluminum ions enables to control the viscosity of the systems adjusting it to the specific reservoir conditions. As a result both the oil displacement factor and reservoir coverage increase.

Based on the studies of the kinetics of hydrolysis, the physicochemical and rheological characteristics of the solutions and sols we have found that after the thermostatting at $70-200{ }^{\circ} \mathrm{C}$ of the system solutions, containing surfactants, carbamide, ammonium and $\mathrm{Al}$ salts, the $\mathrm{pH}$ rises, the viscosity increases 6-78 times, Fig. 4. Prior to the thermostating the solution was a Newtonian fluid and after the solation it became a viscoplastic fluid having properties of both solid and liquid and the ability to exhibit the properties of elastic shape recovery after the stress relief. Oil displacement factor was increased by 5-39\%. The system solutions have demulsifying effect and the amount of water in the oil was decreased 10-220 times.

The created systems have the following physicochemical parameters: the $\mathrm{pH}$ of the solutions - 3.4-4.1 pH units.; the $\mathrm{pH}$ of the sols and gels - 7.7-10.1 $\mathrm{pH}$ units; the viscosity of the solutions $-1.6-3.5 \mathrm{mPa} \cdot \mathrm{s}$; the viscosity of the sols $-9.7-260 \mathrm{mPa} \cdot \mathrm{s}$; the density of the solutions-1161-1178 kg/m 3 ; the gelation time-from several minutes to some days depending on the temperature and composition of the solution; the freezing temperature-minus $20.4-$ minus $21.2{ }^{\circ} \mathrm{C}$. The systems can be used in a wide temperature range, from 70 to $220{ }^{\circ} \mathrm{C}$. They have high technological and economic efficiency and are environmentally safe.

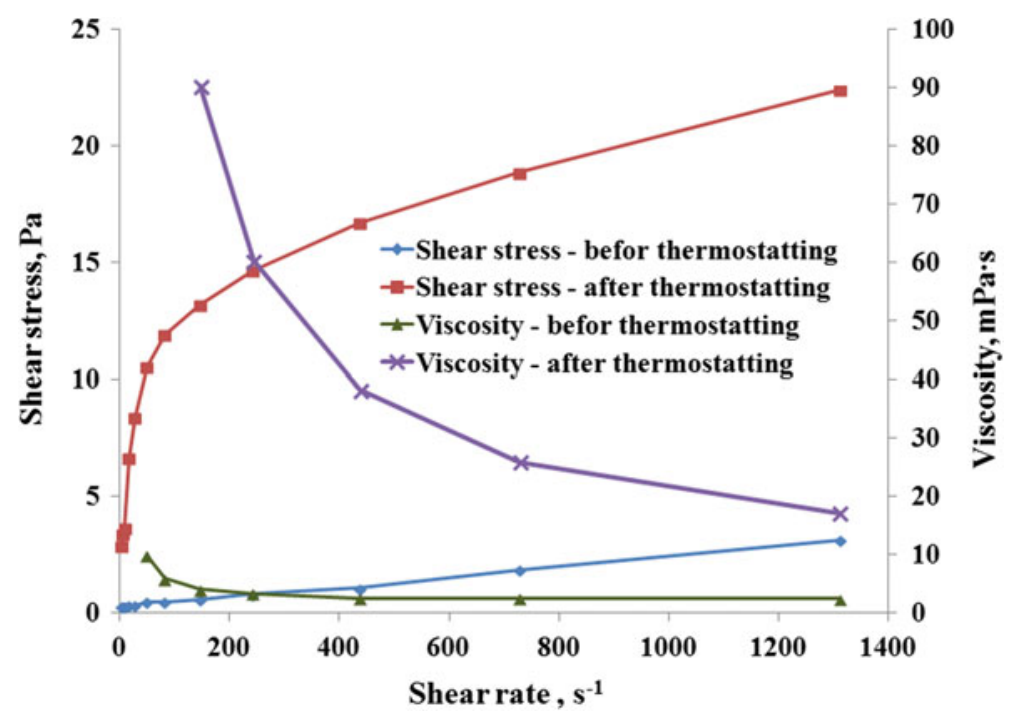

Fig. 4 Total flow curves and viscosity dependence on shear rate for the sol-forming oil-displacing system containing surfactants, carbamide, ammonium and aluminum salts $(2.5 \%)$, before and after $5 \mathrm{~h}$ thermostatting at $150{ }^{\circ} \mathrm{C}$ 
To enhance oil recovery, decrease water cuttings of well production and stimulate oil production under complicated operating conditions, including deposits of high-viscosity oils developed by thermal-steam stimulation, we have created thermotropic systems based on inorganic and polymer systems generating in situ a gel or sol and the sol-forming oil-displacing surfactant-based systems with controlled viscosity and alkalinity. The thermal reservoir energy or that of the injected heat carrier is a factor causing solation and gelation. Laboratory technological regulations for preparing the systems have been developed. The products of large-tonnage chemical production, with a preference for low-cost domestic products are used as the system components. It enables to create effective competition to the existing chemical EOR technologies such as polymer flooding and others.

The thermotropic sol- and gel-forming systems have the following characteristics: can be used in a wide range of reservoir temperatures $\left(20-320{ }^{\circ} \mathrm{C}\right)$; have a low freezing point, homogeneity; retain their viscosity characteristics; exhibit high thermal-oxidative stability in highly saline reservoir waters, up to $300 \mathrm{~g} / \mathrm{dm}^{3}$; high penetrability, stimulate reservoir microflora and can be used in the formations with polymictic, carbonate and other reservoirs of different structure and permeability, from $1 \mathrm{mD}$ to $20 \mathrm{D}$, including low-permeable, highly heterogeneous and fractured reservoirs developed by water flooding or thermal-steam stimulation.

Under reservoir simulating conditions, the filtration characteristics and the oil displacement factors have been determined for typical oilfields of light and high-viscosity oils, in particular for Permian-Carboniferous reservoir in the Usinsk oilfield developed by thermal-steam and cyclic-steam stimulations. A computer model of the deflecting screens formed during the injection of the gel-forming and sol-forming systems has been developed. A calculation method has been created to schedule the systems injections to enhance oil recovery and for water shutoff: calculation of the required amounts of chemicals, scheme of injections and efficiency forecast. Extensible Markup Language XML of MathSoft development environment MathCad v13 is a source language. The text of the program is presented as a sheet of MathCad package.

We have developed the technologies and technological instructions for application of the gel-forming and sol-forming systems at water flooding and thermal-steam stimulation to enhance oil recovery and for water shutoff. Proposed were different variants of the system injections - reagent cycling, gradient, and component-wise. The technology of the component-wise injection of the systems is based on the in situ gelation in the predetermined reservoir place due to hydrodynamic dispersion. The technologies are environmentally safe and can be implemented using standard field equipment.

To study the influence of the developed EOR technologies on the physicochemical properties of oils and formation waters, reservoir microflora, we regularly analyzed oils sampled from the wells in the test areas. In 2014-2016 we analyzed 237 samples of oil and the formation waters from wells of the Permian-Carboniferous reservoir in the Usinsk oilfield. 


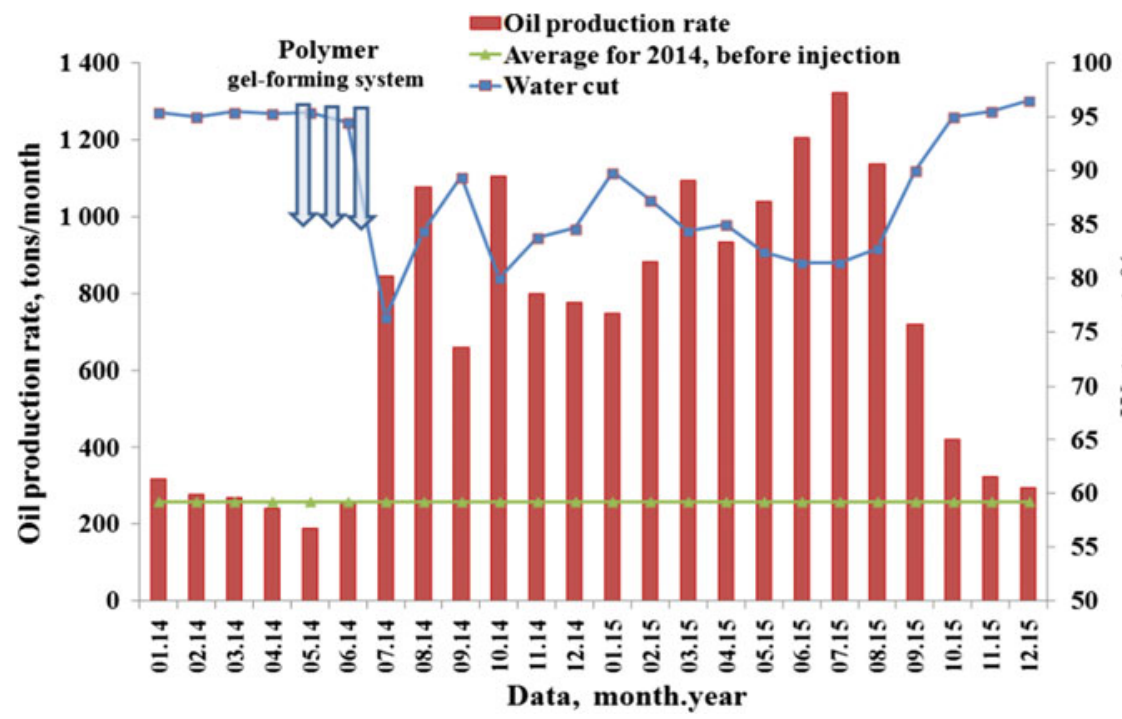

Fig. 5 The results of pilot tests for the water shutoff using the thermotropic polymer gel-forming system total in 5 production wells in the Permian-Carboniferous reservoir of the Usinsk oilfield: increased oil production rate and reduced water cut

In 2014-2016, the EOR technologies were successful tested in the PermianCarboniferous reservoir of the Usinsk oilfield [1, p. 3; 2, p. 10; 5, pp. 280-282]: using the inorganic gel-forming system in three production wells developed by the natural mode, one steam-injection and two cyclic-steam wells; using the thermotropic polymer gel-forming system-in 10 production wells in the test area developed by thermal-steam stimulation and the sol-forming oil-displacing system with the controlled viscosity and alkalinity - in eight steam-injection wells (the effect was calculated for 75 production wells). The testing proved the efficiency of the systems and EOR technologies in the natural development mode and the thermal-steam stimulation. After the injection of the systems one observed a steady decrease in water cut and increase in oil production, Figs. 5 and 6. Thus, in 2014-2015 due to the injection of the sol-forming oil-displacing system in eight steam-injection wells incremental oil production amounted to more than 76,000 tons. The results obtained correspond to the world scientific and technological level. 


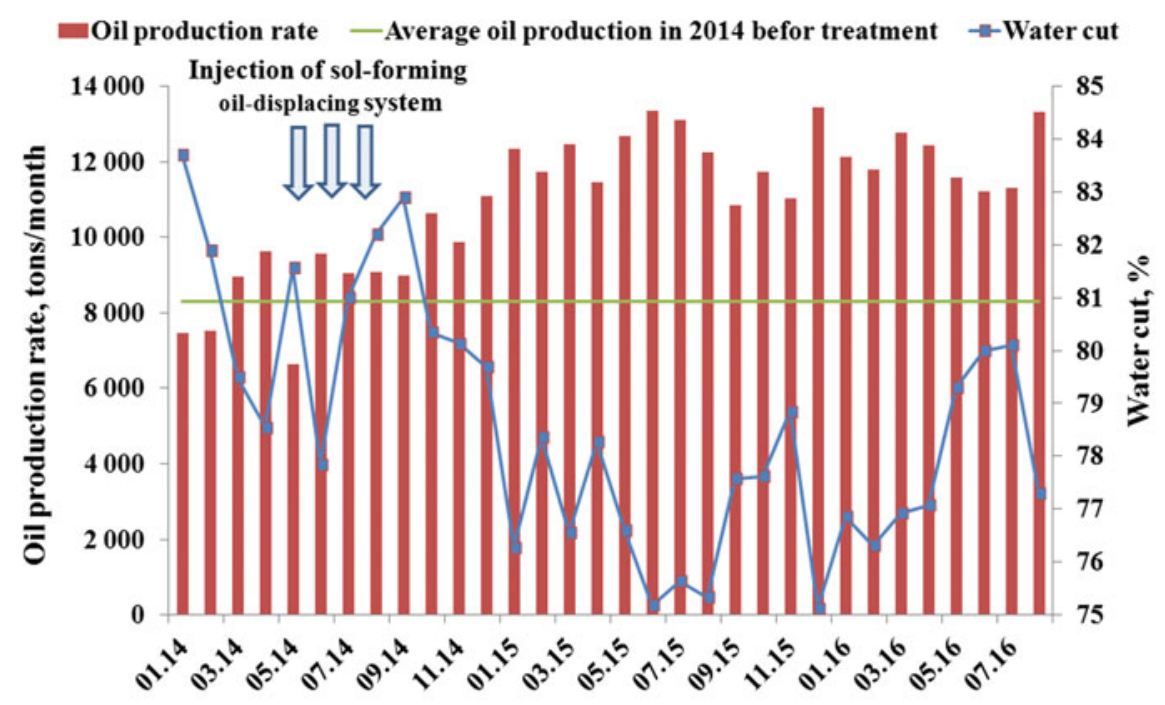

Data, month.year

Fig. 6 Oil production rate and water cut before and after the injection of the sol-forming oil-displacing system at the thermal-steam stimulation in the test area of the Permian-Carboniferous reservoir of the Usinsk oilfield in 2014-2015

\section{Conclusions}

The use of new environmentally safe technologies intended to enhance oil recovery and stimulate oil production will enable to increase the final oil recovery factor by $2-7 \%$; to decrease water cut of well production by $5-30 \%$; to stimulate oil production 1.2-1.3 times and to carry out technological operations in the temperature range of $20-320{ }^{\circ} \mathrm{C}$ and formation water salinity up to $300 \mathrm{~g} / \mathrm{dm}^{3}$. Large-scale commercial application of the newly developed EOR technologies will enable to extend the profitable exploitation of deposits at the later stage of their development and engage in the development deposits with difficult-to-recover hydrocarbon reserves including high-viscosity oil pools and Arctic deposits. It will contribute to the development of the oil industry in Russia and to the expansion of its fuel and energy base.

Acknowlegements Research is carried out with the financial support of the State represented by the Ministry of Education and Science of the Russian Federation. Agreement no. 14.607.21.0022 05. June 2014. Unique project Identifier: RFMEFI60714X0022. 


\section{References}

1. Altunina L.K., Kuvshinov V.A., Kuvshinov I.V.: «Cold» technologies for enhanced oil recovery from high-viscosity oil pools in carbonate reservoirs. In: 7th EAGE saint petersburg international conference and exhibition: understanding the harmony of the earth's resources through integration of geosciences, pp. 16-20. Saint Petersburg (2016)

2. Altunina L.K., Kuvshinov V.A., Chertenkov M.V., Ursegov S.O.: Integrated IOR technologies for heavy oil pools. In: Abstract Book of the 21st World Petroleum Congress, pp. 10-11. Moscow, Russia (2014)

3. Altunina L.K., Kuvshinov V.A., Kuvshinov I.V., Chertenkov M.V., Ursegov S.O.: Pilot tests of new EOR technologies for heavy oil reservoirs. In: Proceedings of SPE Russian petroleum conference, Moscow. Russia (2015). Paper 176703-MS. Flash-memory

4. Altunina, L.K., Kuvshinov, V.A.: Gel-forming METKA ${ }^{\circledR}$ system for selective water shutoff and enhanced oil recovery from Permocarbonic deposit in Usinskoye oilfield. AIP Conf. Proc. 63(1), 37-48 (2008)

5. Altunina, L.K., Kuvshinov, V.A.: Improved oil recovery of high-viscosity oil pools with physicochemical methods and thermal-steam treatments. Georesources. 18(4/1), 277-287 (2008)

6. Korsakova, N.K., Penkovsky, V.I., Altunina, L.K., Kuvshinov, V.A.: Redistribution of filtration flows by thermogel at boundary water flooding of oil reservoirs. AIP Conf. Proc. 1783, 020106 (2016)

7. Romero-Zeron, L.: Chemical enhanced oil recovery (cEOR) - a practical overview. ISBN 978-953-51-2701-7. Print ISBN 978-953-51-2700-0. InTech, 2016. $200 \mathrm{p}$

8. Ruzin L.M., Morozyuk O.A., Durkin S.M.: Features and innovative ways of highly viscous oil field development. Neftyanoe khozyaystvo. 8, pp. 51-53 (2013)

Open Access This chapter is licensed under the terms of the Creative Commons Attribution 4.0 International License (http://creativecommons.org/licenses/by/4.0/), which permits use, sharing, adaptation, distribution and reproduction in any medium or format, as long as you give appropriate credit to the original author(s) and the source, provide a link to the Creative Commons license and indicate if changes were made.

The images or other third party material in this chapter are included in the chapter's Creative Commons license, unless indicated otherwise in a credit line to the material. If material is not included in the chapter's Creative Commons license and your intended use is not permitted by statutory regulation or exceeds the permitted use, you will need to obtain permission directly from the copyright holder.

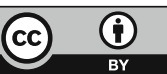

